\title{
FONDO DE AHORRO UNIVERSITARIO
}

\author{
UNIVERSITY SAVINGS FUND \\ Luisa Elena Salcedo Guzmán* \\ Docente asociada de la Facultad de Ciencias Contables - UNMSM \\ Zelma Wong Torres** \\ Docente Principal de la Facultad de Ciencias Contables - UNMSM
}

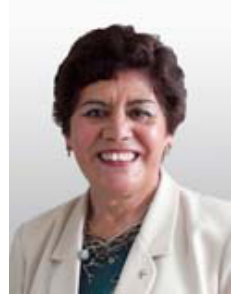

\section{RESUMEN}

El presente artículo busca plasmar los resultados más relevantes que se obtuvieron en el año 2011, como parte del desarrollo del Proyecto de Investigación SIN-SIN, intitulado, Fondo de Ahorro Universitario.

El proyecto tuvo como finalidad esquematizar bajo el modelo de Fondo de Ahorro común, un programa de inversión estudiantil - FONDO DE AHORRO UNIVERSITARIO- en el que el estudiante a través de aportaciones voluntarias pueda acceder a futuros créditos que reditúen sus proyecciones académicas. Hoy un estudio realizado a nivel nacional se observa que solo el $35 \%$ de los estudiantes egresan de una carrera superior y otro porcentaje aún mayor se queda en el intento a causas de situaciones económicas poco favorables. Entonces lo que se buscó con este proyecto fue demostrar que el Fondo de Ahorro Universitario no sólo puede fomentar al hábito del ahorro en los estudiantes sino que además puede ser un mecanismo que mejore su nivel de vida actual o futura.

Palabras Clave: Fondo de ahorro, Programa de Inversión, Aporte estudiantil, Educación Superior.

\begin{abstract}
This article seeks to capture the most relevant results were obtained in 2011, as part of development of the Research Project SIN-SIN, entitled, College Savings Fund.

The project aimed to outline the model of common Savings Fund, an investment program student - university savings fund -in which the student through voluntary contributions to access to future credits redituen their academic projections.

Today, a national study shows that only $35 \%$ of students graduating from a race superior and another percentage is even larger in the attempt to causes of unfavorable economic conditions. So what is sought for this project was to demonstrate that the College Savings Fund can not only promote the savings habit among students but can also be a mechanism to improve their standard of living or future.

Keywords: Savings Fund, Investment Program, Student Contribution, Higher Education.
\end{abstract}

* $\quad$ Egresada de Postgrado - Doctorado, UNMSM; Contadora Pública Colegiada Certificada; Docente Investigadora de la Facultad de Ciencias Contables - UNMSM. Email: luisalcedog@yahoo.es

** Magister en Ciencias Contables, UNMSM; Contadora Pública Colegiada Certificada; Docente Investigadora de la Facultad de Ciencias Contables - UNMSM. Email: zwongt@hotmail.com 


\section{INTRODUCCIÓN}

A modo de referencia, un fondo de ahorro es la previsión social mediante la cual una empresa y sus trabajadores aportan directamente de sus ingresos, una cantidad periódica, con el fin de realizar una reserva financiera (ahorro) para que puedan otorgar financiamiento a todos los trabajadores participantes que regularmente a medio año o al final del año, retiraran el monto total de ambas aportaciones más el importe de los intereses generados por los diferentes financiamientos otorgados. De esta manera los empleados pueden disponer de sus préstamos una vez al año o de acuerdo a las políticas de las empresas. Lo que sí es necesario es que la empresa debe brindar mecanismos que proporcionen una transparente rendición de cuentas, derivada de la confianza de los trabajadores hacia el desenvolvimiento de éste sistema que permita optimizar su rendimiento.

Cuando existe un área de éste tipo en las empresas, se inyectan hábitos de ahorro para los trabajadores, una cultura que al trabajador le permita desprenderse de un recurso económico y a futuro le genere mayores beneficios.

Bajo éste enfoque de Fondo de Ahorro Común, se previó organizar una estructura similar que contenga al Fondo de Ahorro Universitario, generando con ello un producto nuevo e innovador dirigido a satisfacer las necesidades y expectativas de ahorro que tienen jóvenes estudiantes, para el logro de sus metas a futuro.

Las características de este fondo serian distintas a la del sistema financiero, sería mucho más flexible, dependiendo al target al que nuestro servicio va dirigido y con beneficios que el mercado bancario no ofrece: Atractiva rentabilidad a mediano y largo pla- zo, aportación mínima inicial accesible, depósitos que se pueden realizar sin costo de cuenta de ahorro, la posibilidad de ahorrar en forma programada, acceso a una tarjeta de convenios de la propia universidad, acceso a créditos después de los seis meses de afiliación y un mínimo costo en mantenimiento.

\section{MODELOS DE GESTIÓN}

En algunas Universidades de Latinoamérica, como la Universidad de La Sabana en Colombia se ha desarrollado un programa llamado Fondo de Estudiantes, que viene hacer un conjunto de Recursos Económicos que se aplican para financiar inversiones y servicios de Bienestar Universitario, destinados a los estudiantes de Pregrado de la Universidad, adicionales o complementarios a los programas de Bienestar que ofrece la Universidad de La Sabana. Este programa además de ofrecer préstamos económicos a los estudiantes también les ofrecen servicios adicionales.

La gran parte de apoyos económicos que la Universidad de la Sabana brinda a sus estudiantes, se destinan a Actividades académicas que no sean requisito de una materia específica, es decir actividades extracurriculares: Cursos, congresos, seminarios y otros cursos que complementen la formación académica de los estudiantes y que muy pocas veces el estudiante tiene para financiarlo.

El programa desde un inicio fue creado con la finalidad de incentivar la formación integral de los estudiantes de Pregrado a pesar de sus limitaciones económicas. Visto desde este punto, se pudo observar que el índice de graduados y estudiantes que se han visto beneficiados bajo este sistema de autofinanciación (universidad - estudiantes) tuvo un incremento del 30 a $48 \%$ en la Universidad, según su último estudio. 
La Universidad Tecnológica de Panamá, desarrolla actualmente el Fondo de Ayuda Educacional, creado bajo un modelo auto sostenible, que beneficie cada año a estudiantes con dificultades económicas. Este modelo es administrado bajo un modelo de aporte y prestación en el que el Fondo de Ayuda Educacional se incrementará mediante el cobro del capital prestado más el interés fijado por la propia institución, a la vez el estudiante beneficiario se compromete a devolver la suma prestada mediante pagos mensuales por un periodo acordado hasta su cancelación.

\section{LA CULTURA HECHA POLÍTICA}

Una medida hecha noticia fue la política de implementación que realizó el Estado de México, en el que se anunciaba que 822 mil alumnos de educación secundaria y preparatoria recibirán del Gobierno federal la asignación de una cuenta bancaria para un fondo de ahorro que sólo podrán cobrar al concluir sus estudios y que entonces sumaría un monto de 3 mil pesos más intereses.

Esta medida fue tomada como una forma de garantizar la base financiera que los jóvenes necesitan para superar la pobreza extrema, ante una falencia del sistema financiero para la educación superior.

El fondo quedaría en resguardo de la Banca Nacional Social y de Financiamiento, y sería entregado sólo para continuar estudiando, iniciar un proyecto de inversión, mejorar su vivienda o proteger la salud familiar.

Esta medida salvaguardaría aproximadamente a 550 mil graduados de educación media superior que contarían con un respectivo fondo de ahorro, cuyo monto equivale en promedio a nueve meses de ingresos de sus familias, catalogadas entre las de mayor pobreza en el País.

\section{MODELO DE ADMINISTRACIÓN}

Esta debe estar regida por un Reglamento de Fondo de Ahorro de estudiantes en el que se detalle las disposiciones generales de su administración. Asimismo se debe nombrar a un Comité Directivo que respalde la gestión del Fondo de Ahorro. Esta puede estar formada por los siguientes:

a) Directivos

b) Alumnos

c) Técnicos.

d) Administrativos.

Además, en el Reglamento de Fondo de Ahorro de estudiantes se indicará en un capítulo sobre los préstamos a los cuales tienen derechos los estudiantes aportantes del Fondo bajo las consideraciones que el Comité Directivo prevea necesario.

En el presente proyecto se previo necesario un convenio estratégico con una entidad financiera, la misma que respalde el aporte económico de los participantes.

En relación a los préstamos, se considera:

El Fondo de Ahorro tiene por objetivo no sólo crear una cultura de ahorro que ayude a mejorar la calidad de vida de los alumnos universitarios con bajos recursos, sino además ser una herramienta que pueda colaborar con el logro de sus metas académicas.

En relación a las prestaciones se ha previsto la aprobación de los préstamos con intereses blandos a diferencia del mercado financiero común, dividida esta en tres clases de acuerdos a las necesidades:

Préstamo para gastos directos: Con un tope máximo de $\mathrm{S} / .500 .00$

Préstamo para trámites administrativos académicos: Con un tope máximo de S/. 4,000.00. 
Préstamo para Proyecto de Investigación: Con tope de acuerdo a la opinión de especialistas que evalúen el proyecto de Investigación.

Este ítem también debe estar contenido en el Reglamento de Fondo de Ahorro de estudiantes y en él también se debe indicar básicamente que los socios (estudiantes) requieren de un aporte mensual. La cantidad del aporte será prevista por el Comité Directivo.

\section{LA REAL SITUACION DE LAS TASAS DE INTERÉS DE LA BANCA FINAN- CIERA COMÚN:}

El tema de las tasas de interés, es un tema que más controversia genera en el debate económico. Diversos son los motivos que crean esta controversia. Uno de ellos es que las unidades económicas consideran que las tasa de interés son muy elevadas, lo que convierte al crédito en uno de los costos más altos.

Cada vez más personas son proclives a solicitar prestamos personales para temas de financiamiento educativo; sin embargo ello requiere que la persona tenga requisitos que muchas veces tardan meses en gestionar. Ahora, otro problema que redunda el tema es que quien solicita un préstamo realmente desconoce el monto total del interés generado por la entidad financiera, a veces este termina siendo el doble de lo que presto.

\section{ALGUNAS ENCUESTAS}

Solo cuatro de cada diez peruanos comprenden lo que significa una tasa de interés, reveló una encuesta de la Superintendencia de Banca, Seguros y AFP.

El 34\% de los encuestados respondió erróneamente al ser consultado por el costo de crédito o la retribución que recibimos por nuestros ahorros.
La encuesta realizada entre más de 2,200 personas en ocho ciudades del país, indica sin embargo que el $81 \%$ sí analiza sus posibilidades de pago antes de gastar o endeudarse y que un $68 \%$ suele pagar sus cuentas a tiempo.

En cuanto al uso de los servicios financieros, un $35.4 \%$ de los encuestados declaró tener ahorros, pero en su casa, mientras que otro $29.5 \%$ sí usa cuentas bancarias.

La SBS destacó además que el producto financiero más difundido es la cuenta de ahorros. Un $48 \%$ de los encuestados dijo tener cuenta de ahorros, mientras que solo un $28 \%$ dijo contar con tarjeta de crédito.

\section{CONCLUSIONES}

La situación económica de algunos sectores de la población, no permite contar con una adecuada cultura de ahorro, por lo que estudiantes de escasos recursos no pueden concluir sus estudios superiores.

La aplicación del Fondo de Ahorro universitario en otros países ha funcionado como herramienta para estimular el desarrollo de planes a futuro de la población estudiantil.

El establecimiento del reglamento para el Fondo de Ahorro, permitirá que los estudiantes conozcan en qué condiciones se encuentra el manejo de dicho fondo. El período que abarca el ejercicio. Los remanentes como serán distribuidos .Las fechas de préstamos.

Contar con un manual de procedimientos que genere criterios y uso de formatos uniformes, contribuirá a un adecuado funcionamiento del Fondo de Ahorro de los Estudiantes.

El objetivo final del manejo adecuado y transparente del Fondo de Ahorro, permitirá obtener mayores beneficios que redundarán en óptimos resultados, llevando a buen puerto a los estudiantes para el cumplimiento de sus metas. 


\section{REFERENCIAS BIBLIOGRÁFICAS}

1. PETER F. DRUCKER. "La Sociedad Post Capitalista”. Grupo Editorial Norma

2. MICHAEL E.PORTER. "Estrategia Competitiva”. Vigésima Cuarta Reimpresión- México 1997

3. HENRY MINTZBERG. "La Estructuración de las Organizaciones. Ariel Economia-1993
4. CURSO DE MBA. "Estrategia de Gestión”. Edición de Peter Navarro-2005

5. WALTER ANDIA VALENCIA "Proyectos de Inversión”. Colección especializada en proyectos. Reimpresión Abril 2009-Perú

6. NASSIR SAPAG CHAIN. "Proyectos de Inversión". Pearson-Prentice Hall2007 